\title{
Study on Communication Barriers in the Classroom: A Teacher's Perspective
}

\author{
Nilanjana Pal, University of Calcutta, India \\ Santoshi Halder, University of Calcutta, India \\ Abhijit Guha, University of Calcutta, India
}

\begin{abstract}
The present study is undertaken with the objective to analyse the opinion of secondary school teachers regarding barriers in classroom communication. It is evident from the result of the analysis that barriers existmore, or less, though there is significant difference in opinion among the teachers regarding various dimensions of communication. The majority of the teachers opined that barriers were not due to the source of communication (teacher) but the problem lies with the other elements of the process: the classroom environment, the curriculum and the students.
\end{abstract}

Keywords: communication barriers, effective communication, teacher's opinion, dimensions of communication 


\section{Introduction}

Teachers inevitably spend a fair amount of time in class presenting information and giving instruction to facilitate learning. Yet good speaking does not come easily. Standing up to speak in front of a group, even when we are the "authority", generates fear and anxiety. How effective we are as teachers has a great deal to do with how we communicate. We communicate ideas, information and expectations in a variety of ways, through spoken and written media and through gestures and other body language. We need to be aware of how we communicate because we may send unintended messages. Our body language and other nonverbal cues are important modes through which we can generate a positive classroom environment. New technology presents new opportunities for communication. While technology can make communication easier and more convenient, students generally appreciate the opportunity for personal contact and conversation with the teacher.

Communication is the activity of conveying information through the exchange of ideas, feelings, intentions, expectations, perceptions or commands by speech, writing, gestures and by other means between two or more participants. The process requires a source/sender who encodes information in the form of a message which is transmitted through a medium/channel to a recipient who then decodes the message and gives necessary response/feedback.

In classroom communication, it is the teacher (source) who selects and arranges the content (message) the students (recipients) are to learn and decides how best to help them learn (the instructional strategy/medium) and determines how the students' progress will be communicated to them (the feedback channel). This process takes place within a given context or environment. There is a dynamic interplay among these various elements/dimensions of the process. What works for one teacher with one group of students may not be the most effective choice for another teacher with a different group of students.

Effective communication occurs when messages are not distorted during the communication process and communication serves the purpose for which it was planned or designed. However when the desired effect is not achieved, factors which act as obstacles need to be explained with the intention to discover why the communication has been ineffective. These include filtering, selective perceptions, information overload, emotions, language, silence, 
communication apprehension or anxiety, gender difference and many other factors. These barriers to effective communication can retard or distort the message at any stage in the communication process. Effective communication involves conveying clear and concise information. As teachers we should question ourselves, how well have we been able to communicate to our students and how can we better communicate in the future? The better the communication, the better would be their understanding.

\section{Background Reading}

Collins (1997) examined some of the emotional, psychological, practical and social factors that form barriers to communication. He concluded that dialogue between pupils and teachers form a vital part of classroom communication and effective small group activities are important in empowering pupils. Johnson (1997) considered the different forms of verbal and non-verbal communication, cultural communication and communication enhancers. He contended that the classroom should provide a variety of stimuli, a secure comfortable feeling and should be adapted to fit various activities and give some privacy and individuality. According to him the educator must understand the nature of language and dialect difference and must be able to reach the child's level of understanding. Nelson and Wilson (2008) in an article concluded that evidences on the effectiveness of a particular teaching method may be neither sufficient nor necessary and ultimately, each instructor will individually weigh the perceived costs and benefits to decide whether to use a new method of teaching or not and even then trial and error learning is likely. DfEResearch Report (2010) on "Developing a Communication Supporting Classroom Observational Tool" concluded that scores of language learning environment dimension significantly higher than language learning interaction which again was higher than thescores of language learning opportunity. Lunenburg (2010) studied communication, the process, the barriers and improving effectiveness of teaching. He classified barriers into four categories: process barriers, physical barriers, semantic barriers and psychological barriers and stressed on active listening. Okon (2011) studied the role of non-verbal communication in education and concluded that the educators need to develop skills to recognise conflict and employ non-confrontational and non-aggressive responses. The research and analysis of Carmen and Ghinea (2013) is concerned about the possible occurrence of the "Pygmalion effect" a type of self fulfilling prophecy in the classroom. This means the teacher unwillingly takes a course of action that brings about the initially expected result. This behaviour can have 
a major impact on the impressionable learner and this is a more important responsibility on the teachers shoulder than that of imparting knowledge. Behavioural skill building is therefore necessary to provide a solid base for raising expectations. Kovar, Henry and Monsoon (2013) wrote an article examining factors influencing students ratings of instruction. The study concluded that enrolment capacity, room capacity and class size contributed to the statistical variance in student ratings of teaching effectiveness (7.4\%) in a course and the course as a whole (9.3\%). Crowding added environmental stress and thus negative outcomes in classroom but class size hardly contributed to the overall models which implied instructors could be effective (as perceived by students) in larger classes. Pathan (2013) attempted to explore the problems that prevent students from mastering the needed oral communication skills and found that the main barriers of oral communication are inability to discrimination between long and short vowels, failure to pronounce sounds unavailable in first language and mis-application of stress. Inadequate range of vocabulary, passive sentences and reported speeches prevent learners from understanding and conveying a message.

\section{Significance of the Topic}

Within the teaching profession, communication skills are applied in the teacher's classroom management, pedagogy and interaction with the class. In addition, communication skills are important for drawing the learners' attention, developing their motivation and for actively involving them in the teaching-learning process. The focus of this study involves an analysis of the teachers' perceptions regarding their communication strengths and weaknesses, to reveal their attitude - whether they feel that they are potential barriers to classroom communication, or is it, according to their opinion, the ineffective classroom environment, the faulty means/medium of instruction, the inappropriate curriculum, the attitude of students, the lack of response and feedback and other such factors more responsible for ineffective classroom communication.

An investigation of teachers' self-perception is important as their beliefs influence their classroom practice. Teachers' beliefs are embodied in their subconscious and drawn from past experiences. Such beliefs influence teachers' judgement and behaviour which in turn influence what they say and do in classroom. For this reason research about teachers' beliefs and 
perception of their communication skills and the classroom environment is vital and it may help us understand how to overcome the barriers in classroom.

Teachers are primarily not aware of the barriers to their own communication thereby creating distorted or even worse, a total breakdown of communication. The transmission of knowledge that our examination oriented academic system usually requires do not leave any room for enhancement of interpersonal and intrapersonal skills of communication. Once we get a clear understanding of the attitude of teachers, we can endeavour to address the problem.As teachereducators, our primary objective is to make the teachers conscious of their own barriers and later to enable them to identify the barriers their students may be facing. This would allow them greater ease in communication and help bridge the gaps that pose obstacles to effective teaching-learning process.

\section{Methodology}

\section{Purpose of the Study}

The study aims to determine the opinion of secondary school teachers regarding barriers in classroom communication, to evaluate the extent of communication barrier with respect to the different dimensions and to assess the difference in opinion regarding barriers in classroom communication with respect to gender, locality (rural or urban), school types (government or private) and location (Burdwan or Kolkata).

\section{Hypotheses}

The following hypotheses were framed for the study:

1) There is no significant difference in the opinion between male and female teachers regarding barriers to classroom communication.

2) There is no significant difference in opinion of government school and private school teachers regarding barriers to classroom communication.

3) There is no significant difference in opinion of teachers teaching in rural areas and those teaching in urban areas regarding communication barriers in classroom.

4) There is no significant difference in opinion of teachers across districts regarding barriers to classroom communication. 


\section{Sample Selection}

The population for the study comprised teachers of secondary school in and around Kolkata and Burdwan. To test the research objectives, data was collected from Government B.Ed. Training College under the University of Burdwan, B.Ed. Training colleges under the University of Calcutta and Schools in Kolkata. The sample ( $\mathrm{N}=189)$ was drawn by Purposive sampling and this aspect of self-selection may have influenced the results. Due attention was given to the following matching criteria:

(i) All the subjects of the study were teachers teaching at the secondary school level.

(ii) They were trained teachers or in-service teachers on the verge of completing training.

(iii) Teachers having a minimum qualification of Mastersdegree.

(iv) Teachers of the same socio-economic background.

\section{Delimitation}

(i) The study is limited to two districts, Burdwan and Kolkata.

(ii) The study is restricted to secondary school teachers.

\section{Tools}

The data collection instrument was self made questionnaire to study the opinion of secondary school teachers regarding barriers in classroom communication. It had two parts - the first part was general information schedule which contained teacher's demographic information. The second part contained 32 statements regarding the opinion of teachers, covering six dimensions/aspects of barriers to classroom communication. Each statement had three options for response, according to the opinion of the teacher whether each statement was true, partly true or not at all. The statements were scored on a three point Likert scale.

\section{Data Analysis}

The data was analysed for Mean, Standard Deviation and t-test. The latter was carried out to test the significance of the difference in opinion among teachers regarding barriers to classroom communications with respect to each dimension across different demographic characteristics. 


\section{Findings}

It is evident from the result of the analysis (given in Table 1 to Table 4) that there exists significant difference in the opinion of teachers with respect to all dimensions (gender, school type, location, locality) of communication barriers. Thus we reject the null hypothesis that there is no significant difference in the opinion of teachers regarding classroom communication. The mean (M), standard deviation (S.D.) and t-test scores of male and female teachers are shown in Table 1. Significant difference, $(t=6.45)$ is found between males and females regarding barriers to classroom communication. The general opinion of male teachers $(M=1.67)$ is that there exists greater barriers to communication than opined by female teachers $(\mathrm{M}=1.44)$. Differences in opinion were found with respect to all dimensions: classroom environment, medium of communication, feedback from students, their own ability to communicate and with respect to their learners.

Table 1. Mean (M), standard deviation (S.D.) and t-test scores of male and female teachers

\begin{tabular}{|c|c|c|c|}
\hline Dimensions & \multicolumn{2}{|c|}{ Mean (M) \& Standard Deviation (S.D.) } & \multirow{2}{*}{$\begin{array}{c}\text { t-values } \\
\text { Male vs. } \\
\text { Female }\end{array}$} \\
\hline & Male $(\mathrm{N}=51)$ & Female $(\mathbf{N}=138)$ & \\
\hline $\begin{array}{c}\text { Barriers in Classroom } \\
\text { environment }\end{array}$ & $\begin{array}{c}M=1.66 \\
\text { S.D. }=0.39\end{array}$ & $\begin{array}{c}M=1.39 \\
\text { S.D. }=0.39\end{array}$ & $4.32 * *$ \\
\hline $\begin{array}{l}\text { Barriers in medium/means } \\
\text { of communication }\end{array}$ & $\begin{array}{c}M=1.52 \\
\text { S.D. }=0.29\end{array}$ & $\begin{array}{l}M=1.39 \\
\text { S.D. }=0.27\end{array}$ & $2.72 * *$ \\
\hline Barriers in content & $\begin{array}{c}M=1.71 \\
\text { S.D. }=0.39\end{array}$ & $\begin{array}{c}M=1.38 \\
\text { S.D. }=0.36\end{array}$ & $5.42 * *$ \\
\hline $\begin{array}{c}\text { Barriers in } \\
\text { response } \\
\end{array}$ & $\begin{array}{c}M=1.68 \\
\text { S.D. }=0.30\end{array}$ & $\begin{array}{l}M=1.47 \\
\text { S.D. }=0.33\end{array}$ & $3.88 * *$ \\
\hline $\begin{array}{c}\text { Barriers in } \\
\text { source/teacher }\end{array}$ & $\begin{array}{l}M=1.64 \\
\text { S.D. }=0.26\end{array}$ & $\begin{array}{c}M=1.53 \\
\text { S.D. }=0.24\end{array}$ & $2.73 * *$ \\
\hline Barriers in receiver/learner & $\begin{array}{c}M=1.82 \\
\text { S.D. }=0.42\end{array}$ & $\begin{array}{c}M=1.45 \\
\text { S.D. }=0.35\end{array}$ & $6.09 * *$ \\
\hline $\begin{array}{l}\text { Overall opinion regarding } \\
\text { Barriers in Communication }\end{array}$ & $\begin{array}{l}M=1.67 \\
\text { S.D. }=0.22\end{array}$ & $\begin{array}{c}\mathrm{M}=1.44 \\
\text { S.D. }=0.22\end{array}$ & $6.45 * *$ \\
\hline
\end{tabular}

* Significant at 0.05 level ** Significant at 0.01 level

The mean (M), standard deviation (S.D.) and t-test scores of government school teachers and private school teachers are shown in Table 2. Significant difference, $(t=2.37)$ is found between the government and private school teachers in their perception regarding communication barriers. However with respect to the source $(t=0.20)$ and the content $(t=$ 
1.81) of communication the difference in opinion between the two school types is not significant (NS). In all dimensions other than the medium of communication and in general, mean score of government school teachers $(\mathrm{M}=1.52)$ is greater than the mean score of private school teachers $(\mathrm{M}=1.42)$. This indicates government schools are perceived to have less effective classroom communication compared to private schools. Only with respect to medium of communication private school teachers have a higher mean score than government school teachers.

Table 2. The mean (M), standard deviation (S.D.) and t-test scores of government school teachers and private school teachers

\begin{tabular}{|c|c|c|c|}
\hline Dimensions & \multicolumn{2}{|c|}{ Mean (M) \& Standard Deviation (S.D.) } & t-values \\
\hline & $\begin{array}{l}\text { Government School } \\
\text { Teachers }(\mathrm{N}=147)\end{array}$ & $\begin{array}{l}\text { Private School } \\
\text { Teachers }(\mathrm{N}=42)\end{array}$ & $\begin{array}{l}\text { Govt. vs. } \\
\text { Pvt. }\end{array}$ \\
\hline $\begin{array}{c}\text { Barriers in Classroom } \\
\text { environment }\end{array}$ & $\begin{array}{c}M=1.50 \\
\text { S.D. }=0.40\end{array}$ & $\begin{array}{c}M=1.32 \\
\text { S.D. }=0.42\end{array}$ & $2.65 * *$ \\
\hline $\begin{array}{l}\text { Barriers in medium/means } \\
\text { of communication }\end{array}$ & $\begin{aligned} M & =1.40 \\
\text { S.D. } & =0.26\end{aligned}$ & $\begin{array}{l}M=1.50 \\
\text { S.D. }=0.34\end{array}$ & $2.04 *$ \\
\hline Barriers in content & $\begin{array}{c}M=1.50 \\
\text { S.D. }=0.39\end{array}$ & $\begin{array}{c}M=1.37 \\
\text { S.D. }=0.41\end{array}$ & $1.81 \mathrm{NS}$ \\
\hline Barriers in response & $\begin{array}{c}M=1.56 \\
\text { S.D. }=0.33\end{array}$ & $\begin{array}{l}M=1.40 \\
\text { S.D. }=0.31\end{array}$ & $2.77 * *$ \\
\hline $\begin{array}{c}\text { Barriers in } \\
\text { source/teacher } \\
\end{array}$ & $\begin{array}{l}M=1.56 \\
\text { S.D. }=0.25\end{array}$ & $\begin{array}{l}M=1.55 \\
\text { S.D. }=0.25\end{array}$ & $0.20 \mathrm{NS}$ \\
\hline Barriers in receiver/learner & $\begin{array}{l}M=1.60 \\
\text { S.D. }=0.42\end{array}$ & $\begin{array}{c}M=1.38 \\
\text { S.D. }=0.29\end{array}$ & $3.27 * *$ \\
\hline $\begin{array}{l}\text { Overall opinion regarding } \\
\text { Barriers in Communication }\end{array}$ & $\begin{array}{c}M=1.52 \\
\text { S.D. }=0.25\end{array}$ & $\begin{array}{c}M=1.42 \\
\text { S.D. }=0.23\end{array}$ & $2.37 *$ \\
\hline
\end{tabular}

* Significant at 0.05 level ** Significant at 0.01 level

As seen in Table 3, there is significant difference $(t=3.31)$ in the opinion of the teachers teaching in schools of Panchyat area (rural) and those teaching in schools of Municipal areas (urban). If we analyse dimension-wise results we find no significant difference $(t=0.50)$ in opinion regarding the medium of instruction as well as acting as in their own communication $(\mathrm{t}=1.88)$ a barrier to effective classroom teaching. On the contrary there is significant difference regarding classroom environment, contents of teaching, the students and their feedback. Rural teachers find a greater barrier while communicating with their learners as mean score of rural teachers $(M=1.60)$ is greater than mean score of urban teachers $(M=1.47)$. 
Table 3. Difference in the opinion of the teachers teaching in schools of Panchyat area (rural) and those teaching in schools of Municipal areas (urban)

\begin{tabular}{|c|c|c|c|}
\hline \multirow[t]{2}{*}{ Dimensions } & \multicolumn{2}{|c|}{ Mean (M) \& Standard Deviation (S.D.) } & \multirow{2}{*}{$\begin{array}{c}\text { t-values } \\
\text { Rural vs. } \\
\text { Urban }\end{array}$} \\
\hline & $\begin{array}{l}\text { Teachers in Rural } \\
\text { School }(\mathrm{N}=44)\end{array}$ & $\begin{array}{l}\text { Teachers in Urban } \\
\text { Schools }(\mathrm{N}=145)\end{array}$ & \\
\hline $\begin{array}{c}\text { Barriers in Classroom } \\
\text { environment }\end{array}$ & $\begin{array}{c}M=1.57 \\
\text { S.D. }=0.35\end{array}$ & $\begin{array}{c}M=1.43 \\
\text { S.D. }=0.42\end{array}$ & $1.99 *$ \\
\hline $\begin{array}{l}\text { Barriers in medium/means of } \\
\text { communication }\end{array}$ & $\begin{array}{c}M=1.45 \\
\text { S.D. }=0.22\end{array}$ & $\begin{array}{l}M=1.42 \\
\text { S.D. }=0.30\end{array}$ & $0.50 \mathrm{NS}$ \\
\hline Barriers in content & $\begin{array}{l}M=1.61 \\
\text { S.D. }=0.38\end{array}$ & $\begin{array}{l}M=1.43 \\
\text { S.D. }=0.40\end{array}$ & $2.60 * *$ \\
\hline Barriers in response & $\begin{array}{c}M=1.65 \\
\text { S.D. }=0.27\end{array}$ & $\begin{array}{l}M=1.49 \\
\text { S.D. }=0.34\end{array}$ & $2.78 * *$ \\
\hline $\begin{array}{c}\text { Barriers in } \\
\text { source/teacher }\end{array}$ & $\begin{array}{l}M=1.62 \\
\text { S.D. }=0.27\end{array}$ & $\begin{array}{c}M=1.54 \\
\text { S.D. }=0.24\end{array}$ & $1.88 \mathrm{NS}$ \\
\hline $\begin{array}{c}\text { Barriers in receiver/ } \\
\text { learner }\end{array}$ & $\begin{array}{l}M=1.74 \\
\text { S.D. }=0.39\end{array}$ & $\begin{array}{l}M=1.50 \\
\text { S.D. }=0.40\end{array}$ & $3.63 * *$ \\
\hline $\begin{array}{l}\text { Overall opinion regarding } \\
\text { Barriers in Communication }\end{array}$ & $\begin{array}{l}M=1.60 \\
\text { S.D. }=0.19\end{array}$ & $\begin{array}{l}M=1.47 \\
\text { S.D. } 0.25\end{array}$ & $3.31 * *$ \\
\hline
\end{tabular}

* Significant at 0.05 level $\quad * *$ Significant at 0.01 level

The difference in the opinion of school teachers from Burdwan district and that of Kolkata and surroundings can be analysed from Table 4. The mean scores of teachers from Burdwan $(\mathrm{M}=$ 1.69) is greater than the mean scores of teachers from Kolkata $(M=1.42)$. There is significant difference $(t=7.69)$ in the overall opinion as well as with respect to all the dimensions between the teachers of the two regions. The null hypothesis we made is therefore rejected. 
Table 4. The difference in the opinion of school teachers from Burdwan district and that of Kolkata and surroundings

\begin{tabular}{|c|c|c|c|}
\hline \multirow[t]{2}{*}{ Dimensions } & \multicolumn{2}{|c|}{ Mean (M) \& Standard Deviation (S.D.) } & \multirow{2}{*}{$\begin{array}{l}\text { t-values } \\
\text { Kolkata vs. } \\
\text { Burdwan }\end{array}$} \\
\hline & $\begin{array}{c}\text { Teachers } \\
\text { Kolkata } \\
(\mathbf{N}=133)\end{array}$ & $\begin{array}{c}\text { Teachers } \\
\text { Burdwan }(\mathrm{N}=56)\end{array}$ & \\
\hline $\begin{array}{c}\text { Barriers in Classroom } \\
\text { environment }\end{array}$ & $\begin{array}{c}\mathrm{M}=1.35 \\
\text { S.D. }=0.36\end{array}$ & $\begin{array}{c}M=1.72 \\
\text { S.D. }=0.39\end{array}$ & $6.19 * *$ \\
\hline $\begin{array}{l}\text { Barriers in medium/means of } \\
\text { communication }\end{array}$ & $\begin{array}{c}M=1.38 \\
\text { S.D. }=0.27\end{array}$ & $\begin{array}{l}M=1.55 \\
\text { S.D. }=0.29\end{array}$ & $3.90 * *$ \\
\hline Barriers in content & $\begin{array}{l}M=1.36 \\
\text { S.D. }=0.36\end{array}$ & $\begin{array}{c}M=1.73 \\
\text { S.D. }=0.38\end{array}$ & $6.26 * *$ \\
\hline Barriers in response & $\begin{array}{c}\mathrm{M}=1.48 \\
\text { S.D. }=0.32\end{array}$ & $\begin{array}{l}\mathrm{M}=1.64 \\
\text { S.D. }=0.34\end{array}$ & $3.03 * *$ \\
\hline $\begin{array}{c}\text { Barriers in } \\
\text { source/teacher }\end{array}$ & $\begin{array}{l}M=1.52 \\
\text { S.D. }=0.24\end{array}$ & $\begin{array}{c}M=1.66 \\
\text { S.D. }=0.24\end{array}$ & $3.70 * *$ \\
\hline Barriers in receiver/learner & $\begin{array}{l}M=1.44 \\
\text { S.D. }=0.35\end{array}$ & $\begin{array}{c}M=1.82 \\
\text { S.D. }=0.40\end{array}$ & $6.53 * *$ \\
\hline $\begin{array}{l}\text { Overall opinion regarding } \\
\text { Barriers in Communication }\end{array}$ & $\begin{array}{c}M=1.42 \\
\text { S.D. }=0.22\end{array}$ & $\begin{array}{c}M=1.69 \\
\text { S.D. }=0.21\end{array}$ & $7.69 * *$ \\
\hline
\end{tabular}

* Significant at 0.05 level ** Significant at 0.01 level

Analysis of the response to whether external noise affects teaching revealed the following:

(i) $76 \%$ of teachers agreed that external noise disturbed the classroom environment, while

(ii) $24 \%$ disagreed that external noise was a barrier to communication

This is consistent with previous studies that concluded that noise cause environmental stress [Keyton, (2011); Lunenburg (2010); Evans (1982) ] Comparing the statistics of Burdwan and Kolkata shows that

(i) more than $30 \%$ of the teachers of Kolkata are unaffected by external noise,

(ii) while in Burdwan less than $10 \%$ are unaffected by noise

When asked the opinion of teachers regarding the effect of class strength on communication.,

(i) 58\% agreed that huge class size was a problem for their teaching while, (ii) $42 \%$ of teachers were unaffected by class strength.

This finding is consistent with (Evans, 1982 ) who found overcrowding cause stress but is inconsistent with ( Kovar, Henry \& Monson, 2013 ) who found instruction could be effective even in larger classes. 


\section{Discussion}

This study examines the differences in opinion among teachers, regarding barriers to classroom communication, on the basis of gender (male and female), location of the school (Burdwan district or Kolkata and its surrounding), locality (urban or rural) and type of school (Government \& government aided or Private).There are many other factors that may affect communication in the classroom but those are outside the scope of this research.

\section{Gender}

The results of this study indicate that there is significant difference with respect to gender in the perception of barriers to communication within the classroom. The overall result indicates that females feel more at ease while communicating with their learners. Even when we look at individual dimensions, then at every stage of the communication process it is the male teachers who feel more barriers than the female teachers (male mean score $>$ female mean score). This result is inconsistent with (Gopalan et. al; 1998 ) who found women to have greater barriers to information and communication.

Significant differences are noted all the dimensions of communication with respect to gender whether it is regarding the classroom environment, the medium of communication, students response and their motivation, interest or ability. This may be due to the general nature and behavior of women who are found to be move enthusiastic, patient, caring and interactive with young learners.

\section{Type of School}

Comparison between government school and private school teachers indicate significant difference in their respective opinions, regarding the overall presence of communication barriers. However no significant difference was found between the opinion of government school and private school teachers regarding their own ability towards effective communication and also regarding effectiveness of content/curriculum in the teachinglearning process. This may be because all schools whether government or private follow a prescribed curriculum and as the teachers of both government or private schools have the same training and have a minimum qualification of a Masters degree (the sampling selection criteria), they feel they are equally adept at classroom management irrespective of school type. The mean score of 
government school teachers > private school teachers in most of the dimensions (classroom environment, student response, student performance and content) indicating that government school teachers feel a greater barrier while communicating with their learners. Only with respect to the medium of communication, private school teachers have a higher mean score indicating that they find a greater barrier in this respect. This may be because majority of the private schools use English as the medium of instruction and not the mother tongue. Thus language acts as a major barrier for both the teachers as well as the learners (Pathan, 2013).

\section{Locality}

The results of data analysis show a significant difference in the opinion of those teaching in urban locality compared to those in rural areas. The latter perceive a greater difficulty in communication due to significant barriers in classroom environment, in the contents, barriers in response and in the learners. This finding is inconsistent with (DfE RR, 2010) that found urban classrooms had lower language learning opportunities than rural classrooms. One probable explanation of our findings is that many of those attending such schools are first generation learners. The content/curriculum followed in schools do not match their real life experiences and have little relevance from them. However no significant difference was found in the opinion of rural and urban school teachers with respect to barriers in means of instruction and in the source/teacher. Teachers' response shows that they have a positive attitude towards teaching irrespective of the location of school.

\section{Location}

Statistical analysis indicates that the initial hypothesis we made has to be rejected. Significant difference was found in the overall opinion as well as in the opinion regarding specific dimensions of classroom communication between secondary school teachers of Kolkata and Burdwan. The teachers from Burdwan face a greater barrier while communicating with their students than teachers in Kolkata irrespective of their gender and type of school. This regional disparity may be due to specific local factors influencing teaching-learning process in the two districts or socio-cultural factors influencing the teachers, the students and the general classroom environment. 


\section{Limitation}

(i) Constraints with respect to time and cost of administration compelled the researcher to simplify the study.

(ii) Simple random sampling was not carried out because of administrative difficulties. The sample therefore should not be considered representative and some caution should be noted while interpreting the results.

(iii) Some items of the self made questionnaire could have been rephrased to draw out the true attitude of the respondent.

\section{Conclusion}

There are many intervening variables lying between the source and the receiver of communication. A communicator must be aware of the nature and effect of these intervening variables ------ if properly employed the same elements that are barriers to communication become facilitators. A calm, peaceful environment, tension free mutual interaction, proper facilities in terms of multimedia can enhance the effectiveness of the communication process.

The teacher as the source of communication should have proper knowledge of the subject matter and confidence in his knowledge. The overall behaviorand personality of a teacher and the strategies he employs in the classroom also influence his success. It is the teacher's duty to select and modify the content material and make it relevant to the learner's needs, interest and socio-economic background and then present it in a novel manner. But communication can only be carried out effectively with the involvement and co-operation of the students. The students as receivers must have previous knowledge, the general background for receiving and understanding the message and skills such as listening, observing, thinking, analyzing evaluating and drawing inferences. The students must be alert and attentive and must show proper zeal, enthusiasm and curiosity.

The study of communication barriers from a teacher's perspective enabled us to identify the different opinion of teachers regarding classroom communication. There was significant difference in opinion among the teachers regarding various dimensions of communication, but one thing clearly emerges from the study: barriers exist - more, or less. As it is the opinion of teachers, quite naturally the majority of the teachers opined that barriers were not due to the 
source of communication ( the teacher ) but the problem lies with the other elements of the process - the classroom environment, the curriculum and the students. The solution however is with the teachers: to modify the classroom environment, rectify the teaching content and mould the students to achieve their objective of effective teaching-learning. With experience the teachers are able to do much of the impossible. The exact effect of teaching experience on the classroom communication has not been analysed in this study but it certainly deserves a closer look. Further research in this area is recommended to better explain the variance in opinion among teachers. 


\section{References}

Barret, S. (2002). Overcoming Transactional Distance as a Barrier to Effective Communication over the Internet.International Education Journal, 3(4), Educational Research Conference 2002, Special Issue.

Best, J. W., \& Khan, J. W. (2012). Research in Education (10 ${ }^{\text {th }}$ ed.). New Delhi: PHI Learning Private Ltd.

Boyer, T. (2008). Demand for Multimedia in the classroom: Do students and Faculty Really Want it All? (Presentation Paper). American Agricultural Economics Association Annual Meeting, Orlando.

Carmen, S. T., \& Ghinea, V. M. (2013). Pygmalion Teaching Style, Is There a Need For It? Managing \& Marketing Challenges for the Knowledge Society, 8(4), 699-722.

Collins, J. (1997). Barriers to Communication in Schools.(Presentation paper). British Educational research Association Annual Conference, University of York.

Dabaj, F. (2011).Analysis of Communication Barriers to Distance Education.Online Journal of Communication and Media Technologies, 1(1).

DfE Research Report (2010). Developing a Communication Supporting Classroom Observational Tool. Department for Education Research Report-247-BCRP8.

Garrett, H. E., \& Woodworth, R. S. (1981). Statistics in Psychology and Education. Bombay: Vakils, Feffer and Simons Ltd.

Gopalam, S., Chandiram, J., Bhatia, B. S., Kishor, L., \& Lyngdoh, K. S. (1998). Barriers to Information and Communication Technologies Encountered by Women. (Country Presentations). The Commonwealth of Learning.

Huges, S. C., Wickersham, L., Ryan-Jones, D. L., \& Smith, S. A. (2002). Overcoming Social and Psychological Barriers to Effective On-line Collaboration. Educational Technology \& Society, 5(1).

Isman, A., \& Altinay, F. (2005). Communication Barriers: A study of eastern Mediterranean University Students' and Teachers' of Online Programme and Courses. Turkish Online Journal of Distance Education, 6(4), Article 13.

Johnson, M. B. (1999). Communication in the Classroom. Guides-Non-Classroom (055) - Opinion Papers (120).

Kothari, C. R., \& Garg, G. (2014). Research Methodology: Methods and Techniques ( $3^{\text {rd }}$ ed.). Kolkata: New Age International (P) Limited Publishers. 
Koul, L. (2013). Methodology of Educational research (4 ${ }^{\text {th }}$ ed.). New Delhi: Vikas Publishing House Pvt. Ltd.

Kovar, K. A., Henry, A. L., \& Mouson, M. J. (2013). Can we do more with less? Examining Factors Influencing Student Ratings of Instruction (Presentation Paper). Southern Agricultural Economics Association Annual Meeting, Orlando, Florida.

Lunenburg, F. C. (2010). Communication: The Process, barriers and Improving Effectiveness. Schooling, 1(1), Sam Houston State University.

Mangal, S. K., \& Mangal, S. (2013). Research Methodology in Behavioural Sciences (eeed.). New Delhi: PHI Learning Private Ltd.

Mangal, S. K., \& Mangal, U. (2011). Essential of Educational Technology. New Delhi: PHI Learning Private Ltd.

Nelson, R. G., \& Wilson, N. L. W. (2008). Evaluating Teaching Methods: Is it Worth Doing Right? (Presentation Paper). Southern Agricultural Economics Association Annual Meeting, Dallas, Texas.

Okon, J. J. (2011). Role of Non Verbal Communication in Education.Mediterranean Journal of Social Sciences, 2(5).

Pathan, A. K. (2013). Major Linguistic barriers of Oral Communication in English as Perceived by the Tertiary level ESL Students.ISSN 1930-2940, 13(3).

Prep Programme (1999). Communication Skill Development. Retrieved on April 2, 2014 from www.dsnetwokaz.org/PDF/Prep/Part_vPdf.

Sue, D. W., \& Sue, D. (1977). Barriers to Effective Cross-Cultural Counselling. Journal of Counselling Psychology, 24(5), 420-429. 